\title{
Serious Snake Bite Case: Successful Treatment Using Yoga Prana Vidya (YPV) Healing System
}

\author{
Ramya $\mathrm{A}^{1}$, Ashwin $\mathrm{V}^{2}$, Divya $\mathrm{D}^{3}$, Nanduri VS ${ }^{4 *}$ \\ ${ }^{1}$ YPV practitioner-Researcher, YPV Ashram, Sri Ramana Trust, Thally - 635118, Tamilnadu, \\ India Cell\# +91-81470 62216 \\ ${ }^{2}$ YPV Practioner-Researcher, YPV Ashram, Sri Ramana Trust, Thally- 635118, Tamilnadu, \\ India Cell\# +91-8762780709 \\ ${ }^{3}$ YPV practitioner-Researcher, YPV Ashram, Sri Ramana Trust, Thally - 635118, Tamilnadu, \\ India Cell \# +91-8971946570 \\ ${ }^{4}$ Consultant-Research \& Publications, YPV Research, YPV Ashram, Sri Ramana Trust, Thally- \\ 635118, Tamilnadu, India
}

doi: 10.51505/ijmshr.2021.5111

URL: http://dx.doi.org/10.51505/ijmshr.2021.5111

\begin{abstract}
Introduction: Research estimates reveal that over a million bites a year happened in India, of which $70 \%$ cases showed symptoms of envenomation. Prevention, prompt and effective treatment strategies would greatly minimise deaths caused by snakebite.. This study presents a patient's case of complicated snake bite (poisonous viper snake) for which the patient sought help from Yoga Prana Vidya (YPV) healers for treatment.

Main symptoms \& clinical findings: Gangrenous changes in right hand of bitten thumb and high creatinine levels were found from medical examination. Medical prognosis suggested amputation of entire right hand and Dialysis treatment as the situation worsened for her.

Therapeutic interventions \& outcomes: Two YPV healers healed the patient distantly every day for seven days, supported by a senior most healer who gave required additional intensive healing to save the patient. Analysis of data show that gangrenous changes started disappearing after 4 days, and creatinine levels came down to normal within 10 days of healing. There was improved blood flow to right hand with regeneration of tissues and of kidneys. As a result, there was no need to ampute the whole hand, instead, only the bitten thumb was amputed by doctors as a minimal procedure.

Conclusion: Prompt YPV Healing successfully treated the patient thereby avoiding amputation of entire right hand and also avoided dialysis treatment. The evidence gathered from this case indicates that YPV healing is effective in treating complications of snake bite.
\end{abstract}

Keywords: Snake bite, Viper snake, Amputation, Dialysis, Yoga Prana Vidya (YPV) 


\section{International Journal of Medical Science and Health Research}

Vol. 5, No. 01; 2021

ISSN: 2581-3366

\section{Introduction}

\section{Snakebites}

According to WHO, 81,000-138,000 people die each year from snakebites globally, and about thrice as much survive with amputations and permanent disabilities (World Health Organization (WHO), 2019). Suraweera et al. (2020) estimate that India had 1.2 million snakebite deaths (average 58,000/year) from year 2000 to 2019, of which about half occurred in the age range 30-69 years and about a fourth occurred in children younger than 15. Rural homes and farms are known to be most vulnerable places of snake bites. Approximately $70 \%$ of fatal incidents happened in eight Indian states identified to be Bihar, Jharkhand, Madhya Pradesh, Odisha, Uttar Pradesh, Andhra Pradesh including Telengana, Rajasthan and Gujarat. The estimate for 2015 in India showed 1.11-1.77 million bites, of which about $70 \%$ showed symptoms of envenomation. Prevention and treatment strategies are expected to substantially reduce snakebite mortality in India.

A Snakebite is a wound caused by the bite of a snake, especially a poisonous snake, resulting in redness, swelling, and severe pain at the area, which may take up to an hour to appear. Typical symptoms are tingling of the limbs, sweating, vomiting, and blurred vision. Most bites are on the hands, arms, or legs. Fear following a bite is common with symptoms of a racing heart and feeling faint. The consequences of a snakebite are: breathing problems, bleeding, severe allergic reaction, kidney failure, and dead tissue around the bite. The extent of suffering depends on the type of snake, the area of the body bitten, the amount of venom injected, and the general health of the person bitten. Children are more susceptible to consequences of snakebite than adults, due to more intense effect in comparison (Wikipedia, 2020). Poisonous snakes exist in every continent except Antarctica. The World health organization says snakebites are a "neglected public health issue in many tropical and subtropical countries", and in 2017, WHO categorized snakebite envenomation as a neglected tropical disease (Category A) with the purpose to promote research and improve management of this issue in developing countries (Wikipedia, 2020a). The Russell's viper is one of the most dangerous snakes in all of Asia, accounting for thousands of deaths each year and they exist mostly in Southeast Asia including India, Sri Lanka, Pakistan, Myanmar and Taiwan (University of Michigan, 2008). The victim may feel pain within ten minutes of snake bite, and if medical help is not immediately available death can occur in as little as 2.5 hours. The poison from snakebite can affect kidneys severely needing dialysis, as frequently as 3 times per week, to save the victim.

\section{The Yoga Prana Vidya (YPV) System}

The techniques of Yoga Prana Vidya healing have been found to successfully treat and cure difficult medical cases (Neravetla \& Nanduri, 2019), self-healing case of high blood cholesterol levels and asthma (Nanduri \& Vasavada, 2019), addressing eye problems and achieving improvements of Vision (Nanduri \& Chaitra, 2019), treating EXOSTOSIS of ear without surgery (Gupta \& Nanduri, 2019), successful management of Post-Herpetic Neuralgia (PHN) (Sachdeva \& Nanduri, 2019), treatment of heart block case patient without surgery (Ramya \& Nanduri, 2019), management and control of diabetes (Ashalatha, Ramya \& Nanduri ( 2019). A one-month 


\section{International Journal of Medical Science and Health Research}

Vol. 5, No. 01; 2021

ISSN: 2581-3366

intensive YPV residential programme enabled the participants to improve physical and mental health parameters (Neravetla \& Nanduri, 2020).

YPV system is integrated and holistic with wide range of healing protocols, and includes physical exercises, breathing techniques, diet, forgiveness sadhana, meditation and energy-based healing (Yoga Prana Vidya Research, 2019). By using this system, for example in case of a heart patient, three effects take pace simultaneously: (1) heart will function properly, (2) experience peace within, and (3) strengthening of body's immune system, recovery happening at all levels. Human physical body is contained within the energy body, which is also called Bio-Plasmic body and this energy body comprises of 5 major units, known as inner aura, outer aura, health rays, chakras and Nadis (Powell, 1997). One's energy body shrinks when sick, and thereby cracks and holes occur in the energy body (see Fig. $1 \& 2$ ), resulting in leaks and loss of energy. The person's health rays are entangled, flow of energy is reduced considerably in nadis and chakras. The YPV techniques consist of cleaning the affected part and increasing energy flow around the aura, and energizing the affected part. When a person is injured, the same phenomenon of loss of energy occurs.

A GDV camera photograph (Figure 4), is a valuable tool to scientifically visualize one's energy body to ascertain the differences before and after YPV healing. This technique, known as BEO GDV (full form: Biological Emission and Optical Radiation Stimulated by Electromagnetic Field Amplified by Gaseous Discharge with Visualization by Computer Processing") gives BEOgrams or GDV-grams. The GDV Camera device is accepted and certified in some countries such as Russia as a medicine tool and can be used in hospitals and medicine centers without limitations and certification process is taking place in Europe as well (Korotkov, 2007).

Similar to pumps and channels in a farm field to circulate irrigation water, there are energy pumps and energy channels in the energy body. The energy pumps are called chakrams and the pipelines are called meridians. Till the basic chakram (shown in Fig.3) is working well, a person can survive. Till the Heart chakram (shown in Figure 3) is big, the patient's heart has chances of survival. To reduce the stress or tension, the Solar chakram (Figure 3) is to be treated. Till
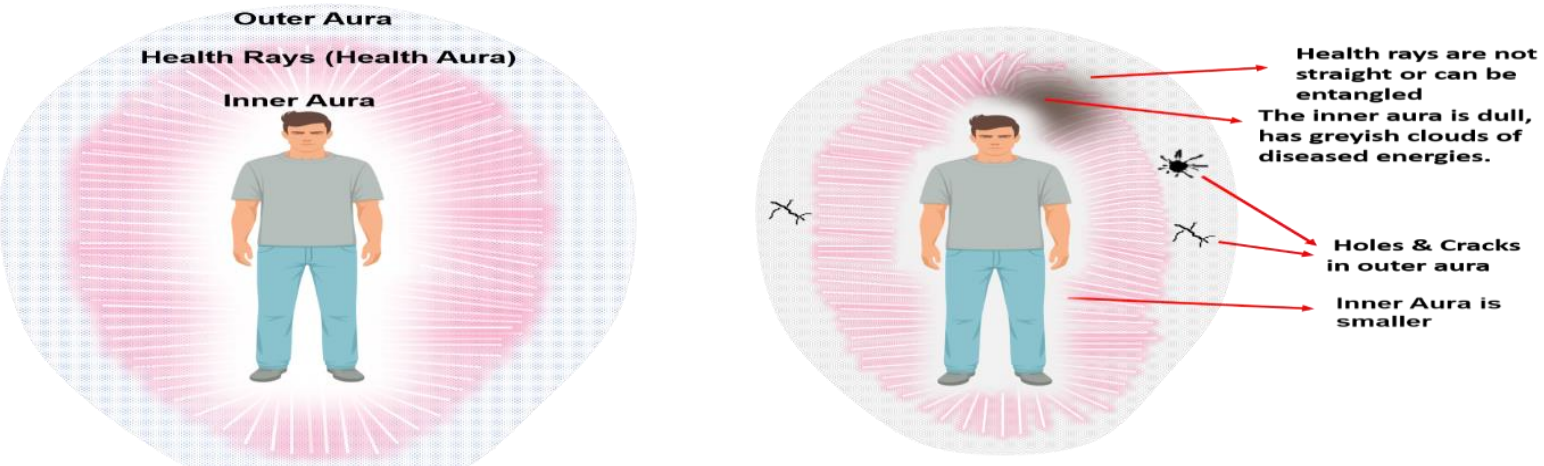

1: Energy body of a healthy person Fig 2: Energy body of a sick person 
the Basic chakram is alive and active, nothing unfortunate will happen to the patient. Simple YPV techniques such as, Rhythmic Yogic Breathing (RYB), proper diet, Forgiveness sadhana (to forgive everyone and ask for Forgiveness), and Planetary peace

Meditation (to bless the planet earth and its inhabitants for bringing peace on the planet Earth) will make the Heart chakram bigger. Preventive YPV healing can also be complementary healing when a subject is at such a place where medical help cannot be reached.

\section{Chakrams}

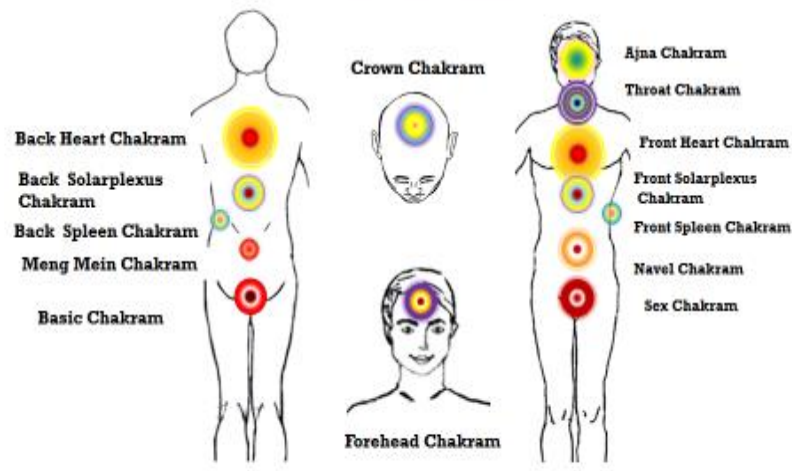

Fig 3: Chakrams or Energy Centres

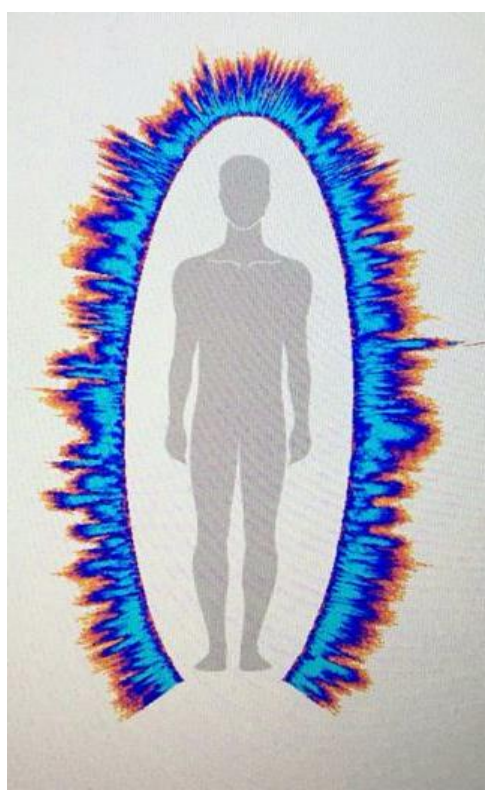

Fig 4: Picture of Human Aura taken with GDV camera

(Source for Figures 1, 2, 3\& 4: YPV Research) 


\section{International Journal of Medical Science and Health Research}

Vol. 5, No. 01; 2021

ISSN: 2581-3366

YPV System places high importance on consuming right food. During illness people should take light food; preferably fruit diet, raw diet, minimum boiled food and avoid salt, fried food and refined sugar (all refined products must be avoided).Food from mineral kingdom has less energy than food from plant kingdom. Nothing can compare with fruit diet (it is pre-cooked and mostly pre-digested), and hence patients and sick people should essentially go on fruit diet.

Another factor dealt with by YPV healing is Stress due to various factors and is also associated with any sickness or injury. Physical indicators of stress are sweating, hands shaking and heart palpitation, and a mind not in control. YPV aims to bring the mind in control as a first step by administering proper breathing using a technique called Rhythmic Yogic Breathing (RYB). The RYB cannot be replaced by any medicine. Thus Yoga Prana Vidya (YPV) healing is a science that offers a range of proven first aid techniques in dealing with emergencies or stand alone or complementarily with other systems such as Allopathy.

\section{Method}

This study uses single in-depth case study method examining available patient case medical records to extract and compile the relevant data identifying salient points in patient injury, sickness, YPV healing protocols used and patient recovery. The healers' own experience in treating the patient fully is also a vital input data in this case.

\section{Case report:}

\section{Main symptoms \& clinical findings:}

A 45 year old female (patient) was working in a farmon 29-09-2018, around $10 \mathrm{am}$. At that time she got bitten by a poisonous viper snake on her right thumb. Immediately her family members took her to a traditional (nati Vaidya) practitioner, who gave medication to take twice in a day, this medicine continued for 2 days, but with no improvement in the patient condition.

On $1^{\text {st }}$ October 2018, they took her to an Ayurveda hospital. By then her condition got worsened and she developed gangrenous changes in her right hand (See Fig 5). After examining the patient she was referred to a multispecialty hospital in Mysore who suggested for amputation of entire right hand with no assurance on her life.

Again on $2^{\text {nd }}$ October 2018, the patient was taken to a government Hospital in Mysore, who also suggested to ampute her entire right hand. By this time her kidneys also got damaged badly, creatinine increased to higher level, and the doctors suggested to go also for dialysis treatment.

\section{Therapeutic interventions \& outcomes:}

Two YPVhealers conducted therapeutic healing on the patient distantly every day for seven days, supported by a senior most healer who gave required additional intensive healing to save the patient.

On $2^{\text {nd }}$ October 2018, when the YPV healing started, creatinine level was $6.1 \mathrm{mg} / \mathrm{dl}$. Thereafter, by regular frequent healings, the creatinine level came down gradually to normal range by $6^{\text {th }}$ October and further to middle range i.e. $0.78 \mathrm{mg} / \mathrm{dl}$ by $12^{\text {th }}$ October 2018 (See Table 1). Also, the blood circulation to right hand improved considerably. By seeing all these positive changes the 
doctors suggested to go only for amputation of right thumb instead of amputation of entire right hand and also avoided dialysis as blood creatinine level was normal by then.

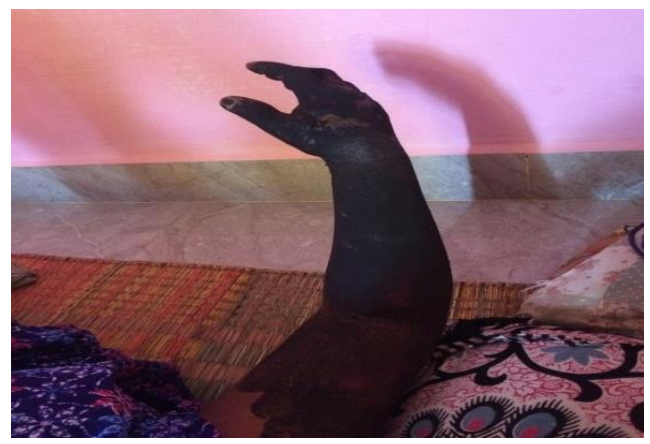

Fig. 5

Table 1: Creatinine levels from Lab reports

\begin{tabular}{|l|l|l|}
\hline Date of Report & Creatinine level in $\mathrm{mg} / \mathrm{dl}$ & Ref range in $\mathrm{mg} / \mathrm{dl}$ \\
\hline $02 / 10 / 2018$ & 6.1 & $0.4-1.4$ \\
\hline $03 / 10 / 2018$ & 3.8 & $0.4-1.4$ \\
\hline $04 / 10 / 2018$ & 2.8 & $0.4-1.4$ \\
\hline $05 / 10 / 2018$ & 2.2 & $0.4-1.4$ \\
\hline $06 / 10 / 2018$ & 1.2 & $0.4-1.4$ \\
\hline $08 / 10 / 2018$ & 0.9 & $0.4-1.4$ \\
\hline $12 / 10 / 2018$ & 0.78 & $0.4-1.4$ \\
\hline
\end{tabular}

It can be observed from Fig 6 that gangrenous changes disappeared after receiving 4 days of healing because of improved blood circulation.

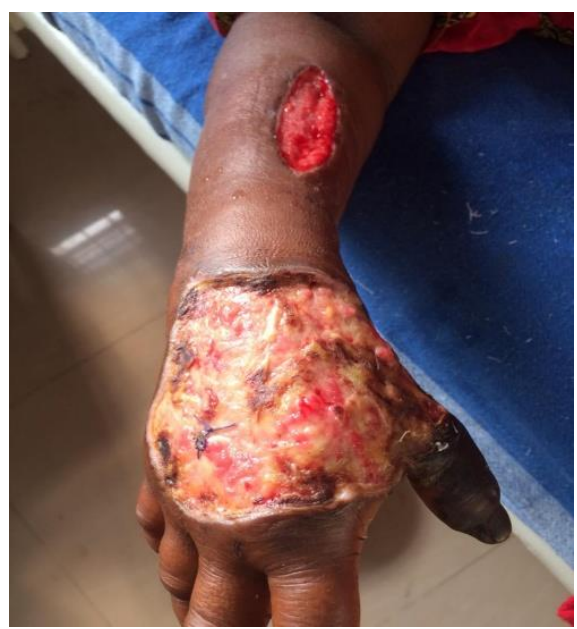

Fig 6: Image shows condition of hand after 6 days of snake bite 


\section{International Journal of Medical Science and Health Research}

Vol. 5, No. 01; 2021

ISSN: $2581-3366$

Fig 7 below is a picture of right hand taken after 10 days of healing, showing the condition of the hand with right thumb amputed to save the full hand.

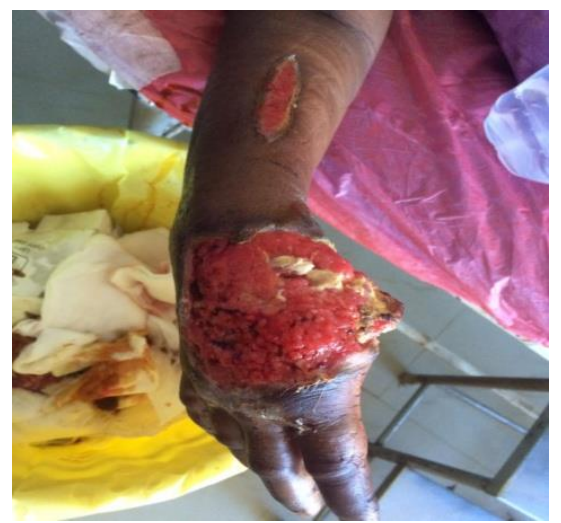

Fig. 7

\section{Discussion}

Analysis of the case documents and observations on the patient show positive results of improvements obtained with YPV healing method used by the healers. Medical investigation after YPV healing confirmed that there is improved blood flow to right hand with regeneration of tissues and of kidneys.

Amputation is the removal of a limb due to trauma, medical illness, or surgery. As a surgical measure, it is used to control pain or a disease process in the affected limb, such as malignancy or gangrene. In some cases, it is carried out on individuals as a preventive surgery for such problems (Wikipedia, 2020a). An amputation usually involves hospitalization of from five to 14 days or more, depending on the complications. The procedure itself may vary, and when performing an amputation, the surgeon removes all damaged tissue while leaving as much healthy tissue as possible (WebMD, 2020).

Dialysis is a treatment that does some of the things done by healthy kidneys. It is needed when your own kidneys can no longer take care of your body's needs. Dialysis is needed when the patient develops end-stage kidney failure, usually by the time the patient loses about 85 to 90 percent of kidney function. When kidneys fail, dialysis keeps the body in balance by (National Kidney Foundation, 2020):

- Removing waste, salt and extra water to prevent them from building up in the body

- Keeping a safe level of certain chemicals in your blood, such as potassium, sodium and bicarbonate

- Helping to control blood pressure.

It is observed in this study that the YPV system healing in distance mode worked well in increasing blood flow to the gangrenous right hand and normalizing blood creatinine level of the 


\section{International Journal of Medical Science and Health Research}

Vol. 5, No. 01; 2021

ISSN: 2581-3366

patient, thereby regenerating the cells of kidneys and hand, and saving the patient life by avoiding amputation of entire right hand and need of dialysis treatment.

Yoga Prana Vidya (YPV) healing protocols apply the bio-field energy principles (Ross, 2019) to direct abundantly available Pranic energy to chakras and organs of human body to heal for recovery from various ailments, including infectious diseases (Neravetla\& Nanduri, 2019). Scientists in US recognised that healing practices that purport to sense and modulate "Subtle energies" of the body have existed for thousands of years in a wide range of cultures (Jain \& Mills, 2019). This family of practices, which includes healing touch (HT), Johrei, Pranic Healing, Reiki, Qigong and Therapeutic Touch (TT), is increasingly referred to as Biofield Therapies, a term that emerged during the US National Institutes of Health Conference in 1992 (Jain et al., 2015).

Biofield therapies, also called energy healing, may be delivered in one or both types, known as proximally, (i.e., with the healer and the subject in the same room) or distally (with the healer and the subject not in the same room; in some cases, separated by hundreds or even thousands of miles). Distal treatment is usually called distance healing which is the method followed by the healers in this case. Distance Healing Intention Therapies (such as the one in this case) have been subjected to scientific scrutiny (Radin, Schlitz, \& Baur, 2015) and observed that some significant effects of distance healing (DHI) have been achieved in experimental trials.

YPV System of Healing follows the principle of natural ability of the human body to heal itself at a certain rate. By increasing the energy level of the affected part or the entire body, the rate of healing can be accelerated several times, there by resulting in fast recovery. Distant healing protocols are being very successfully practiced when patients from any location seek healing help from a healer located elsewhere. Numerous patient feedback reports are documented and available in Yoga Prana Vidya Ashram archives and are verifiable (Yoga Prana Vidya Research, 2019).

\section{Conclusions}

The expertise gained after decades of experience in energy healing, and the evidence at hand find that YPV healing system is very effective as complementary to mainstream medicine in successfully handling emergency cases (such as snakebite in this case) and also various types of sicknesses, with speedy recovery of patients. Yoga Prana Vidya is an integrated System that is holistic in healing the patients with possibilities of permanent cure. These protocols and techniques can be taught by a certified YPV Trainer, and practiced by all concerned in Complementary and Alternative modalities in healthcare.

\section{Acknowledgments}

Thankful acknowledgements to Sri Ramana Trust for permission given to use their copyright terms Yoga Prana Vidya ${ }^{\circledR}$ and YPV ${ }^{\circledR}$.

\section{Funding}

None 


\section{International Journal of Medical Science and Health Research}

Vol. 5, No. 01; 2021

ISSN: 2581-3366

\section{Conflicts of interest}

None

\section{References}

Gupta, K \& Nanduri, V.S. (2019).A case report of the Exostosis of ear of an elderly female: Successful healing with Integrated Yoga Prana Vidya (YPV) healing approach as alternative to surgical intervenetion. Ann Geriatrics Educ Med Sci 2019 6(2): $42-47$

Jain, S \& Mills, P.J. (2009). Biofield Therapies: Helpful or Full of Hype? A Best Evidence Synthesis. Int. J. Behav. Med. (2010) 17:1-6 DOI:10.1007/s12529-009-9062-4

Jain, S., Hammerschlag, R., Mills, P., Cohen, L., Krieger, R., Vieten, C \& Lutgendorf, S. (2015).Clinical Studies of Biofield Therapies: Summary, methodological challenges, and recommendations. Global Adv Health Med2015;4(\#):58-66. DOI: 0.7453/

Korotkov, K. (2007). Diagnosis and monitoring of the human energy-informational state and analysis of subtle energies, applying Gas Discharge Visualization technique, based on the Kirlian method. Retrieved from http://gdv-energiecoaching.be/wpcontent/uploads/2012/05/2007-GDV-Overview-article. Pdf

Nanduri, V.S. \& Vasavada, A. (2019).Successful healing treatment of high blood cholesterol levels and asthma using Yoga Prana Vidya (YPV) system: A case study of self-healing. Panacea Journal of Medical Sciences, September-December, 2019; 9(3): 1 31-13 7

Nanduri, V.S., \& Chaitra, N. (2019).How the participants of a Yoga Prana Vidya (YPV) Eye Camp experienced vision improvements: A Case study. The Journal of Community Health Management. (2019) 6(4):

National Kidney Foundation. (2020). Dialysis - Procedure, types, risks, purpose | National Kidney foundation Oct 30, 2020, www.kidney.org > content > dialysis info Neravetla J \& Nanduri, V.S. (2019). A study into successful treatment of some difficult

Medical cases using Yoga Prana Vidya (YPV) Healing System as alternative medicine. International Journal of Scientific \& Engineering Research Volume 10, Issue 7, July2019, 882-887, (ISSN 2229-5518)

Neravetla, J \& Nanduri, V.S. (2020).A study of the effects of Yoga Prana Vidya one month intensive residential programme for participants on their physical health, psychological well-being and improved immunity. International Journal of Research and Analytical Reviews (IJRAR), 7(2), 18-27.

Powell, A E. (1997). The Etheric Double: The Health Aura of Man. Wheaton IL (USA): Quest Books (Revised edition January 1, 1997).

Radin, D., Schlitz, M \& Baur, C. (2015). Distant healing intention therapies: An overview of the scientific evidence. Retrieved from http://deanradin.com/evidence/evidence.htm

Rajkumari, S \& Nanduri, V.S. (2019).Management of Post-herpetic Neuralgia (PHN) by 


\section{International Journal of Medical Science and Health Research}

Vol. 5, No. 01; 2021

ISSN: 2581-3366

Yoga Prana Vidya (YPV) healing: A case study. American J of Bio-medical and Life sciences, Vol.7 No.6, 2019, pp.174-178

Ramya A, Nanduri VS. (2019). Cardiac Case Study: Successful Healing Treatment of a 48-YearOld Male with Block in Heart, Using Yoga Prana Vidya (YPV) Healing System. Saudi J Nurs Health Care, Nov 2019; 2(11): 353-356.

Rajagopal, A.H., Ashwin R \& Nanduri, V.S. (2019).Diabetes Management and Control Using Yoga Prana Vidya (YPV) Healing System. Journal of Biology and Life Science ISSN2157-6076 2019, Vol. 10, No. 2

Ross CL (2019). Energy Medicine: Current Status and Future Perspectives. Glob Adv Health Med.; 8:2164956119831221. Published 2019 Feb 27. doi:10.1177/2164956119831221

Suraweera, W., Warrell, D., Whitaker, R., Menon, G, Rodrigues, R., Hang Fu, S, Begum, R., Sati, P., Piyasena, K., Bhatia, M., Brown, P., \&Jha, P. (2020) Trends in snakebite deaths in India from 2000 to 2019 in a nationally representative mortality study. eLife 2020;9:e54076 DOI: 10.7554/eLife.54076

University of Michigan. (2008). Russell's viper. Retrieved from http://umich.edu/ elements/web_mod/viper/introduction.htm

Wikipedia (2020a) Amputation-en.wikipedia.org>wiki>Amputation. Retrieved from https://en.wikipedia.org/wiki/Amputation

Wikipedia. (2020b).Snakebite. Retrieved from https://en.wikipedia.org/wiki/Snakebite WebMD. (2020). Limb Amputation: Reasons, Procedure, Recovery-WebMD, Feb 5,2020 www.webmd.com> A to Z Guides > Reference

World Health Organization (WHO). (2019). Snakebite envenoming. WHO Press. Retrieved from https://www.who.int/newsroom/fact-sheets/detail/snakebite-envenoming [Accessed August 1, 2019].

Yoga Prana Vidya Research. (2019). 11 Compiled volumes of case reports. Available with YogaPrana Vidya Ashram, Sri Ramana Trust. 